DOI: https://doi.org/10.24867/14BE09Pavlovic

\title{
IMPLEMENTACIJA PROGRAMABILNIH LOGIČKIH KONTROLERA SA FUZZY LOGIKOM U UPRAVLJANJU STAMBENIM OBJEKTIMA
}

\section{IMPLEMENTATION OF PROGRAMMABLE LOGIC CONTROLLERS WITH FUZZY LOGIC IN RESIDENTIAL BUILDINGS}

\author{
Tijana Pavlović, Fakultet tehničkih nauka, Novi Sad
}

\begin{abstract}
Oblast - ELEKTROTEHNIKA I RAČUNARSTVO
Kratak sadržaj - U ovom radu je programiran programabilni logički kontroler u programskom okruženju TIA portal kako bi se upravljalo pametnom kućom sa sistemom grejanja i hlađenja zasnovanim po principu fazi (engl. fuzzy) logike.
\end{abstract}

Ključne reči: programabilni logički kontroler, fuzzy logika, SCADA, HMI.

\begin{abstract}
In this paper, a programmable logic controller is programmed in the TIA portal programming environment in order to control a smart home with a heating and cooling system based on the principle of fuzzy logic.
\end{abstract}

Keywords: programmable logic controller, fuzzy logic, SCADA, HMI.

\section{UVOD}

$\mathrm{U}$ početku, automatizacija je imala primenu u industriji, dok danas nalazi primenu i u ljudskom životu olakšavajući mu svakodnevnicu. Jedno od najčešćih primena automatizacije u modernom dobu predstavlja pametna kuća. Pametna kuća sa svojim uređajima i sistemima olakšava i pruža udobniji život. Moderan život je konstantno ubrzan i ljudi su skloni zaboravljanju, može se reči da pametna kuća pamti umesto njih i ona je ta koja umesto ljudi isključuje uređaje i time omogućava sigurnost okoline i manju potrošnju energenata i novca, što je svakako cilj svakog čoveka.

Termin „Pametan dom“ odnosi se na pogodno podešavanje kuće gde se uređajima može automatski upravljati sa bilo kog mesta pomoću Internet veze. Uređaji u pametnom domu međusobno su povezani putem Interneta, što omogućava korisniku da daljinski kontroliše funkcije poput bezbednosnog pristupa domu, temperature, osvetljenja, alarma i slično.

\section{PAMETNE KUĆE}

Suština sistema pametne kuće je da omogući jednostavno upravljanje svim sistemima koji se automatski prilagođavaju potrebama i navikama korisnika. Uređaji pametne kuće povezani su međusobno i može im se

\section{NAPOMENA:}

Ovaj rad proistekao je iz master rada čiji mentor je bio dr Velimir Čongradac, red. prof. pristupiti preko jedne centralne tačke - pametnog telefona, tableta ili laptopa. Sistem je instaliran na mobilnom uređaju ili drugom umreženom uređaju i korisnik može da kreira vremenske rasporede da bi određene promene stupile na snagu.

Pametni kućni aparati isporučuju se sa veštinama samoučenja, tako da mogu da nauče rasporede vlasnika kuće i da izvrše prilagođavanja po potrebi. Neki sistemi za automatizaciju kuće upozoravaju vlasnika ako se u kući detektuje bilo kakvo kretanje kad ih nema, dok drugi mogu nazvati vlasti - policiju ili vatrogasce - u slučaju neposrednih situacija.

Sistem omogućava realizaciju velikog broja međusobno povezanih funkcija, uključujući: kontrolu i regulisanje rasvete, kontrolu roletni, regulisanje grejanja, hlađenja i ventilacije, sigurnosne sisteme i monitoring, centralnu automatizaciju i sl. [1].

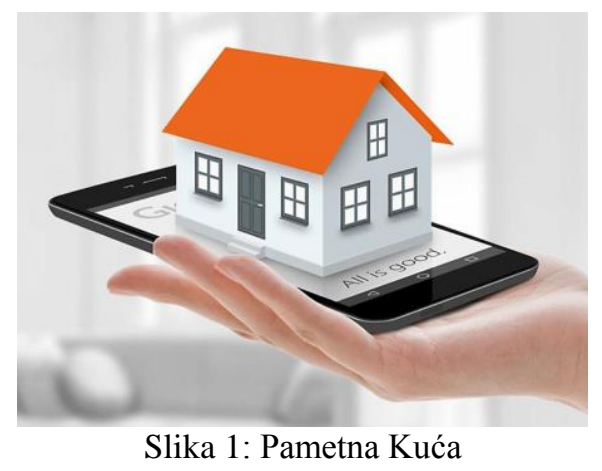

\section{FUZZY LOGIKA}

Fazi logiku je 1965. godine uveo dr Lotfi A. Zadeh u svom radu pod nazivom „Fuzzy sets“. U pitanju je logika koja koristi stepen pripadnosti elementa skupu umesto odrednice da element ili pripada ili ne pripada skupu. Fazi logika nam obezbeđuje mehanizam za reprezentaciju jezičkih konstrukcija kao što su na primer: mnogo, malo, visok, nizak, sredina, često, itd. Uopšteno, fazi logika nam obezbeđuje strukturu koja omogućava sposobnost ljudskog rezonovanja do neke granice.

Ulazi i izlazi mogu imati različite lingvističke nazive. Uobičajeno se promenjive nazivaju opisnim imenima, poput: nivo vode, priliv vode, ljudi srednjeg rasta, velike zarade, brzi automobili, mala rastojanja itd.

Transformaciju ovakvih izraza u oblik matematičke predstave omogućava nam teorija fazi skupova. 
Fazi modeliranje iskaza ukazuje na mogućnost da se fazi regulator formira kao skup pravila kojima se izražava veza između registrovanih vrednosti na izlazu sistema $i$ upravljanja koje treba da promeni te izlaze, odnosno da ih dovede do željenog ishoda. Otuda je kao prvo neophodno da se izvrši izbor ulaznih i izlaznih promenljivih regulatora.

Proces korišćenja fazi sistema obuhvata sledeće faze:

1. Fazifikacija - je faza koja modifikuje signale ulaza tako da mogu biti pravilno protumačeni i upoređeni sa pravilima u bazi pravila. Klasičan, jasan (engl. crisp) signal pretvaramo u adekvatan fazi oblik.

2. Zaključivanje na osnovu pravila - predstavlja mehanizam za procenjivanje koja kontrolna pravila su relevantna za trenutno stanje sistema i odlučuje logičkim sklopom kakav će biti upravljački signal, tj. ulaz u proces.

3. Defazifikacija - transformiše fazi oblik $u$ klasičan oblik signala, koji je „razumljiv“ procesu [2].

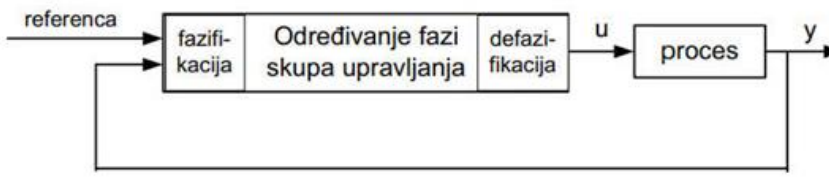

Slika 2: Struktura fuzzy regulatora

\section{PROGRAMABILNI LOGIČKI KONTROLER}

Programabilni logički kontroler (engl. Programmable logic controller - PLC), je računar namenjen za upotrebu $\mathrm{u}$ industrijskim okruženjima, koji se može programirati tako da obavlja upravljačke funkcije. Programabilni logički kontroler je projektovan tako da prihvata više različitih rasporeda ulaza i izlaza, podnosi širok opseg radnih temperatura, neosetljiv je na električni šum i otporan je na vibracije i udarce. Programi koji upravljaju proizvodnjom mašina $i$ opreme najčešće se smeštaju u memoriju koja je trajna ili ima vlastito napajanje. PLC je primer sistema koji radi u realnom vremenu, pošto stanje na izlazima sistema kojim upravlja PLC, zavisi od stanja na ulazima tog sistema. Prema tome, programabilni logički kontroler je u suštini digitalni računar koji je projektovan za upravljanje određenom mašinom ili postrojenjem.

\subsection{Princip rada PLC-a}

Prihvatanje ulaza, obrada i ispis izlaza se ciklički ponavlja u skladu sa programom, određene dužine trajanja, zavisne od broja ulaza i izlaza i složenosti algoritma i vrste primenjenog procesora. Programski ciklus se sastoji od četiri faze.

Pri inicijalizaciji, pri uključenju, PLC prvo proverava moguće greške u svom hardveru i softveru. Ako ih ne pronađe, preuzima stanja ulaza (iz registara ulaza) i kopira njihove vrednosti u memoriju na zato predviđene lokacije. Taj postupak se naziva ulazni sken, a podaci u memoriji se nazivaju slika ulaza.
Koristeći ulazne podatke, odnosno njihovu sliku, procesor izvršava programske naredbe kojima su definisane odgovarajuće aritmetičko-logičke funkcije u fazi koja se naziva programski sken.

Pri tom se rezultati obrade smeštaju u zato predviđeno memorijsko područje nazvano slika izlaza. Po završetku programskog skena $\mathrm{u}$ fazi nazvanoj izlazni sken podaci iz slike izlaza prenose se na izlaze (registre izlaza) [3] [4].

\subsection{SCADA sistem}

SCADA (engl. Supervisory Control and Data Acquistion) sistem je običan sistem procesne automatizacije koji se koristi da prikuplja informacije pomoću senzora i instrumentacije koji su locirani na udaljenim lokacijama kako bi se ti podaci preneli i prikazali na centralnoj lokaciji koja služi ili za upravljanje ili za svrhe monitoringa. Prikupljeni podaci se obično mogu videti na jednom ili više SCADA Host računara koji su locirani na centralnom ili master sajtu.

\subsection{Operatorski panel - HMI}

- Operatorski panel (engl. Human Machine Interface HMI) je interfejs prema korisniku koji omogućava grafički prikaz trenutnog stanja sistema kao i podešavanje parametara koji se odnose na upravljački algoritam.

Iako se termin tehnički može primeniti na bilo koji ekran koji omogućava korisniku interakciju sa uređajem, HMI se najčešće koristi u kontekstu industrijskog procesa.

$\mathrm{U}$ industrijskim okruženjima, operatorski paneli se mogu koristiti za vizuelno prikazivanje podataka, praćenje vremena proizvodnje, nadgledanje ulaza i izlaza mašina [5].

\section{IMPLEMENTACIJA}

U ovom radu, programiranje je izvedeno uz pomoć programskog jezika SCL korišćenjem funkcijskog bloka. Funkcijski blok (engl. Function block - FB) olakšava izradu aplikativnog softvera PLC-a uklanjanjem potrebe za ponavljanjem pisanja iste programske logike. Funkcijski blok je koncipiran tako da prihvati ulaze iz glavnog organizacionog bloka (engl.

Organization block - OB), funkcije (engl. Function - FC) ili funkcijskog bloka gde se poziva i generiše izlaze na osnovu tih ulaza i programske logike samog funkcijskog bloka.

Funkcijski blok je po svojoj ulozi sličan funkciji, ali sa jednom velikom razlikom, a to je da funkcija koristi zajednički memorijski prostor PLC-a za čuvanje vrednosti dok funkcijski blok zahteva dodatni blok sa podacima za čuvanje vrednosti.

Za svaki poziv funkcijskog bloka potreban je novi blok podataka koji se naziva pripadajući blok podataka (engl. Instance data block - IDB).

Prilikom upotrebe funkcijskih blokova moguće je koristiti multi-instanciranje, tako što se u jednom funkcijskom bloku pozove više funkcijskih blokova čiji blokovi podataka će biti smešteni u pripadajućem bloku podataka glavnog funkcijskog bloka koji ih poziva. 


\begin{tabular}{|c|c|c|c|c|c|}
\hline Setpoint / Temperatura & 10 & 15 & 20 & 25 & 30 \\
\hline 10 & No change & Cool 25\% & Cool $50 \%$ & Cool 75\% & Cool $100 \%$ \\
\hline 15 & Heat $25 \%$ & No change & Cool $25 \%$ & Cool $50 \%$ & Cool $75 \%$ \\
\hline 20 & Heat $50 \%$ & Heat $25 \%$ & No change & Cool 25\% & Cool $50 \%$ \\
\hline 25 & Heat $75 \%$ & Heat $50 \%$ & Heat $25 \%$ & No change & Cool $25 \%$ \\
\hline 30 & Heat $100 \%$ & Heat $75 \%$ & Heat $50 \%$ & Heat $25 \%$ & No change \\
\hline
\end{tabular}

Slika 3: Tabela pravila

\section{HMI PAMETNE KUĆE-REALIZACIJA SISTEMA}

Implementacija PLC-a pruža mogućnost upravljanja stambenim objektom koji predstavlja pametnu kuću. Pametna kuća se sastoji od 5 prostorija (slika 6.1): kupatilo, dnevna soba, spavaća soba, kuhinja i kupatilo.

Funkcije koje su implementirane mogu se podeliti u dve grupe: spoljašnje i unutrašnje.

Spoljašnje se sastoje od senzora detekcije noći, spoljašnje temperature, rasvete $\mathrm{i}$ autorizacije prisustva odnosno zaštite od provala.

Unutrašnje funkcije su raspoređene po prostorijama koje se nalaze u kući i to na sledeći način: kupatilo poseduje senzor prisustva, senzor osvetljenja, senzor za detekciju poplave, ventilaciju $\mathrm{i}$ informaciju o statusu glavnog ventila za dotok vode.

Hodnik, dnevna i spavaća soba poseduju senzor prisustva, senzor osvetljenja, senzor za detekciju požara, ventilaciju $\mathrm{i}$ informaciju o položaju roletni.

Kuhinja poseduje senzor prisustva, senzor osvetljenja, senzor za detekciju poplave i požara daje informaciju o statusu glavnog ventila za dotok vode.

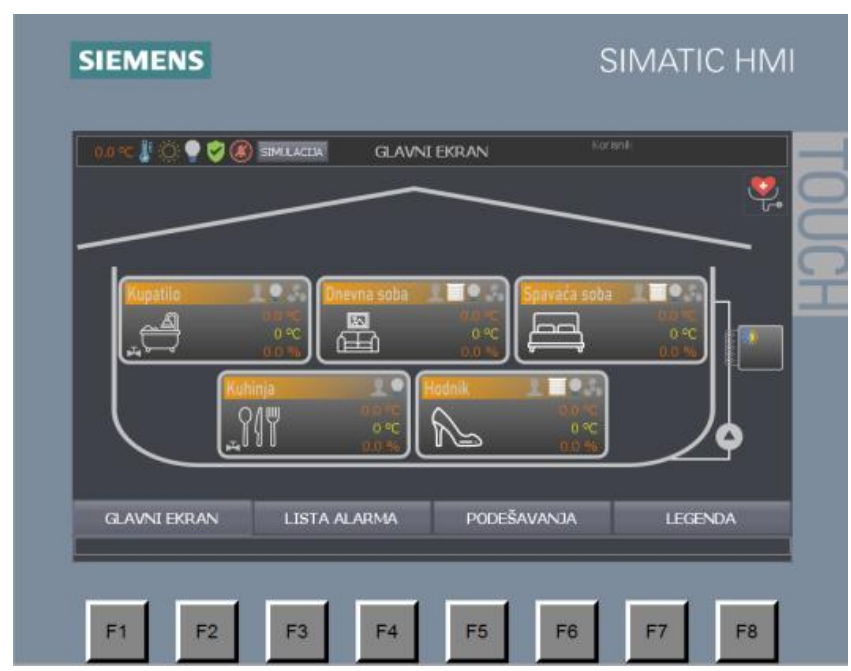

Slika 4: Izgled pametne kuće

\subsection{Simulacija sistema}

Na svim ekranima je vidljivo dugme SIMULACIJA koje vodi do simulacionog ekrana na kom je predstavljena simulacija celog sistema.

Ulaskom u kuću aktivira se tajmer koji korisniku daje vremena da unese šifru i time razoruža zgradu, ako vreme istekne, sistem će smatrati da je došlo do provale i aktiviraće se alarm.

Kada je kuća razoružana ispravno, senzor prisustva detektuje ulazak u prostorije i na osnovu njegovog signala uključuje se svetlo, ventilacija, aktivira se fan coil i cirkulaciona pumpa, dobija se njena potvrda o radu i podižu se roletne.

Vreme kada su roletne podignute unosi se preko panela. Izlaskom iz prostorije, posle određene vremenske zadrške, isključuje se svetlo, ventilacija, automatski se fan coil podešava da bude na željenoj temperaturi koju korisnik unese.

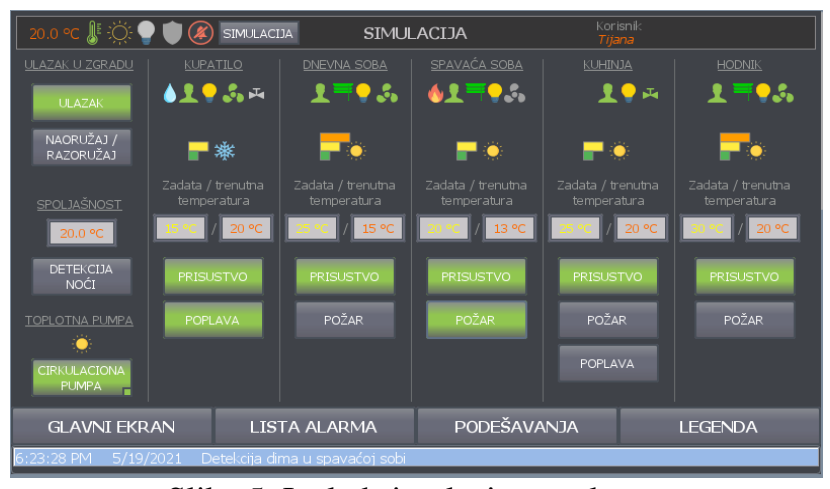

Slika 5: Izgled simulacionog ekrana

Na slici se može videti da se pojavom poplave u kupatilu simbol za ventil promenio iz zelene u sivu boju što označava da je ventil za glavni dotok vode zavrnut. Pojavom požara u spavaćoj sobi, simbol ventilacije menja boju iz zelene u sivu, što znaci da se automatski ventilacija isključuje kada dođe do požara.

\section{ZAKLJUČAK}

U radu je opisana izrada pametne kuće pomoću PLC-a. Bilo je potrebno napraviti program koji upravlja kućom i operatorski panel za kontrolu i nadzor. U programskom alatu TIA portal kreiran je operatorski panel, izrađen program i uspostavljena komunikacija između PLC uređaja i operatorskog panela za kontrolu i nadzor. Testiranje je napravljeno na simulacionom ekranu. U izradi zadatka korišćen je Siemens SIMATIC S7-1200 PLC.

Fazi logika i fazi skupovi su se pokazali kao prirodno rešenje za upravljanje grejanjem i hlađenjem na osnovu temperatura. $U$ ovom radu je odrađena priprema za fazi upravljanje time što se od ulaza razmatra samo trenutna $\mathrm{i}$ zadata temperatura.

Daljom nadogradnjom softvera je moguće upotpuniti fazi upravljanje. Moglo bi se posmatrati više ulaza, npr. vremenska prognoza za narednih nekoliko dana, da li je neka prostorija na sunčanoj strani kuće, vremenski interval kada se kuva, koliko je ljudi u prostoriji itd. Na osnovu toga bi se upravljalo grejanjem i hlađenjem. 


\section{LITERATURA}

[1] Članak o pametnim kućama

http://pametne-kuce.rs/komfor

[2] F. Kulić: „Inteligentni upravljački sistemi“, Fakultet tehničkih nauka, Univerzitet u Novom Sadu, 2014

[3] Specifikacija Programabilnih logičkih kontrolera https://cache.industry.siemens.com/dl/files/465/36932465 latt_106119/v1/s71200_system manual_en-US_en-

US.pdf

[4] Predavanje o programabilnim logičkim kontrolerima http://elektronika.elfak.ni.ac.rs/_FILES/sandra.djosic/4\%2 Oplc.pdf

[5] Primena i programiranje programabilnih logičkih kontrolera

https://www.elektronika.ftn.uns.ac.rs/et-industrijska-

elektronika/wp-

content/uploads/sites/137/2018/03/PRIMENA-I-

PROGRAMIRANJE-mitsubishi-PLCova-FX3S.pdf

\section{Kratka biografija:}

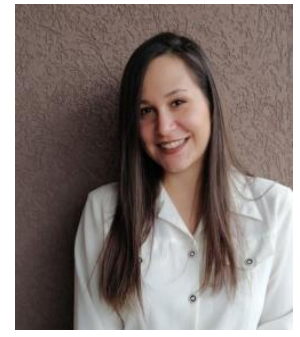

Tijana Pavlović rođena je u Valjevu 1995. god. Master rad na Fakultetu tehničkih nauka iz oblasti Elektrotehnike i računarstva - Totalno integrisani sistemi automatskog upravljanja odbranila je 2021.god.

Kontakt: tijanaa95@yahoo.com 